\title{
lodine plus $n-3$ fatty acid supplementation augments rescue of postnatal neuronal abnormalities in iodine-deficient rat cerebellum
}

\author{
Amit Pal ${ }^{1,2}$, Vishwa Mohan ${ }^{1}$, Dinesh R. Modi ${ }^{2}$, Rohit A. Sinha ${ }^{1}$, Leena Rastogi ${ }^{1}$, Praveen Kumar ${ }^{3}$ \\ and Madan M. Godbole ${ }^{1,3 *}$ \\ ${ }^{1}$ Department of Endocrinology, Sanjay Gandhi Postgraduate Institute of Medical Sciences, Lucknow 226014 , \\ Uttar Pradesh, India \\ ${ }^{2}$ Department of Biotechnology, Babasabeb Bhimrao Ambedkar University, Lucknow 226014, Uttar Pradesh, India \\ ${ }^{3}$ Department of Molecular Medicine E Biotechnology, Sanjay Gandhi Postgraduate Institute of Medical Sciences, Lucknow \\ 226014, Uttar Pradesh, India \\ (Submitted 6 July 2012 - Final revision received 12 November 2012 - Accepted 12 November 2012 - First published online 14 January 2013)
}

\section{Abstract}

High prevalence of hypothyroxinaemia in iodine-deficient (ID) mothers has serious implications for mental health of the progeny. Independent supplementation of iodine and $n-3$ fatty acids (FA) markedly improves growth and cognitive performance of school children. Discerning effects of $n-3$ FA and iodine on the developing cerebellum have not been ascertained. The present study investigates effects of these two micronutrients separately as well as together in an ID rat model. We studied the effects of these micronutrients on progeny of ID dams by instituting the following supplementation diets: (1) low-iodine diet (LID), (2) LID+ potassium iodide (KI), (3) LID+ $n$-3 FA and (4) LID $+\mathrm{KI}+n-3$ FA. Pups were investigated for morphological and biochemical parameters at the peak of cerebellar histogenesis on postnatal day (P) 16 and for neurobehavioural as well as motor coordination parameters at P40. Results indicate that $n$-3 FA alone, without improvement in circulating thyroid hormone (TH), significantly improves functional, morphological and biochemical indices of the developing cerebellum. Further, results show that co-supplementation with iodine and $n$ - 3 FA rescues not only the loss of neurotrophic support, but also salvages motor coordination, memory and learning. This additive effect results in significantly improving neurotrophic support and seems to be mediated by parallel significant increase in TH receptor (TR) $\alpha$ and normalisation of TR $\beta$, retinoic orphan receptor $\alpha$ and p75 neurotrophin receptor, as well as noteworthy prevention of apoptotic cell death and strengthening of anti-oxidative defence. The overall results indicate important mitigating role that $n-3$ FA may play in enhancing TH nuclear receptor-mediated signalling in the developing cerebellum.

\section{Key words: $\boldsymbol{n}$-3 Fatty acids: Iodine deficiency: Neuronal development}

Perinatal iodine nutrition influences thyroid hormone (TH) availability essential for neurodevelopment of the child. Salt iodisation has been introduced in many countries to control iodine deficiency. Assessment of global and regional iodine status, as of 2011, shows an increase in number of countries with adequate iodine intake ${ }^{(1)}$. Implementation of universal salt iodisation programmes has resulted in eradicating the serious problem of neurological cretinism. However, globally, $29.8 \%$ (241 million) of school-aged children are estimated to have insufficient iodine intakes, with the majority living in Asia and Africa. Although iodine nutrition has been improving since 2003, global progress may be slowing ${ }^{(1)}$.
Thus, a mild or moderate degree of iodine deficiency still persists due to tardy implementation of universal salt iodisation in many rural communities of third world countries. Resultant thyroxine deficiency (hypothyroxinaemia) is 150-200 times more common compared with frank hypothyroidism in human subjects in iodine-deficient areas ${ }^{(2)}$. Maternal as well as neonatal hypothyroxinaemia may lead to neurocognitive delays, memory loss and learning deficits ${ }^{(3,4)}$, and they are correctable with adequate iodine nutrition. At the molecular level, iodine is required for the synthesis of TH, namely triiodothyronine (T3) and thyroxine (T4), which are secreted by the thyroid gland. TH bind to their nuclear receptors in

Abbreviations: BDNF, brain-derived neurotrophic factor; FA, fatty acid; FT4, free thyroxine; GSH, glutathione reductase; LID, low-iodine diet; NGF, nerve growth factor; NT-3, neurotrophin-3; P, postnatal day; p75NTR, p75 neurotrophin receptor; ROR, retinoic orphan receptor; T3, triiodothyronine; T4, thyroxine; TH, thyroid hormone; TR, thyroid hormone receptor. 
developing brain and regulate the expression of genes like neurotrophins and their receptors, which are critical for normal brain development. Under perinatal hypothyroidism, enhancement of cerebellar apoptosis and modulation of antioxidative defence have been reported ${ }^{(5,6)}$. Neuronal loss has been ascribed to impaired neurotrophic signalling and increased proteolysis of p75 neurotrophin receptor (p75NTR) ${ }^{(7)}$.

Recent data revealed that $n$ - 3 fatty acids (FA) could have a prophylactic role in preventing the developmental brain damage of hypothyroidism ${ }^{(8)} \cdot n-3$ FA are essential to sustain neuronal function, to protect synapses and neuronal circuits. $n-3$ PUFA potently decrease serum lipids, which is also an effect of $\mathrm{TH}^{(9)}$. DHA, the main member of the $n-3$ essential FA family, is avidly retained and concentrated in the nervous system and is known to play a role in neuroprotection, memory and vision ${ }^{(9)}$. Recent findings suggest that the increase in TH signalling in the liver may be one of the mechanisms by which $n$-3 FA exert part of their effects on lipid metabolism $^{(9)}$.

Lipids are the most abundant biomolecules found in the brain after water. Mechanisms of $n-3$ FA action on the developing brain, in general, can be divided into properties conferred by lipid-bound DHA in the membrane bilayer and those related to unesterified DHA. Interestingly, unesterified DHA, like TH, appears to have roles in regulating gene expression. Both PPAR and liver $\mathrm{X}$ receptor have been shown to be nuclear receptors for $n-3$ FA and are known to have similar site specificity on DNA as TH receptors (TR). These apparent similarities in the molecular mechanism of action of TH and $n-3$ FA prompted us to see whether they could have overlapping molecular targets and compensatory effects. Considering the hypolipidaemic effect of TH and $n-3$ PUFA, together with a previous demonstration of interactions between TR and PPAR pathways in the regulation of lipid metabolism $^{(10-12)}$, we tested, in the present study, the hypothesis that supplementation of $n-3$ FA alone or in combination with iodine would enhance $\mathrm{TH}$ action in the brain and may salvage iodine deficiency-induced loss of cerebellar morphology and function. In order to test this hypothesis, we evaluated the cerebellar expression of TR, retinoic orphan receptor (ROR) and neurotrophins along with neuronal and motor functions in an iodine-deficient perinatal rat model. We also checked specific staining of cerebellum Purkinje cells, molecular layer dendrites and axonal fibres, as well as expression of antioxidant defence enzymes and apoptosis in the developing cerebellum.

Results indicate that, surprisingly, $n-3$ FA alone without enhancement of circulating TH improve functional, morphological and biochemical indices of the developing cerebellum. Results further show that co-supplementation with iodine and $n-3$ FA rescues not only the loss of neurotrophic support, but also improves motor coordination, memory and learning. This improvement of neurotrophic support seems to be mediated by a parallel increase in $\mathrm{TR} \alpha$ and normalisation of TR $\beta, \operatorname{ROR} \alpha$ and p75NTR. The overall results indicate the important role that $n$ - 3 FA may play in enhancing $\mathrm{TH}$ nuclear receptor-mediated signalling in the developing cerebellum.

\section{Materials and methods}

\section{lodine-deficient model (hypothyroxinaemic model)}

The present study on iodine deficiency-induced hypothyroxinaemia and cerebellar development was reviewed and approved by the institutional animal care ethics committee at the Sanjay Gandhi Postgraduate Institute of Medical Sciences institutional animal care ethics committee, which follows the guidelines published by the Committee for the Purpose of Control and Supervision on Experiments on Animals, Government of India. The low-iodine diet (LID) was prepared by thoroughly mixing $6 \mathrm{~kg}$ flour of maize grown in a well-known iodinedeficient area with a recurrent flooding history, $2.5 \mathrm{~kg}$ of wheat gluten, $1.0 \mathrm{~kg}$ brewer's yeast, $0.15 \mathrm{~kg} \mathrm{NaCl}$ and $0.15 \mathrm{~kg}$ $\mathrm{CaCO}_{3}$. Diet was fortified with $16 \mathrm{ml}$ of maize oil equivalent of $15 \mathrm{~g} / \mathrm{kg}$ of diet ${ }^{(13)}$. A sufficient amount of LID was prepared to cover a complete experiment within the same batch.

Female rats aged $50 \mathrm{~d}$ and weighing 120-150g were switched to a LID diet. They were given $1 \% \mathrm{KClO}_{4}$ in drinking-water for $10 \mathrm{~d}$ for removal of stored iodine in their thyroid gland. Animals were then separated into two groups, namely: (1) iodine-sufficient group (LID + KI (10 $\mu$ g iodine/ $20 \mathrm{~g}$ of diet + normal drinking-water)) and (2) LID group $\left(\mathrm{LID}+0 \cdot 005 \% \mathrm{KClO}_{4}\right)$. Both the groups were kept on the afore-mentioned diet regimen for 3 months.

At the end of 3 months, approximately $1.0 \mathrm{ml}$ of blood was obtained under slight diethyl ether anaesthesia. It was centrifuged and the separated serum was stored at $-20^{\circ} \mathrm{C}$ for hormone estimation. Total serum T4, free T4 (FT4) and total T3 were measured by specific RIA using Coat-A-Count Siemens Healthcare diagnostics kits (Siemens Health Care Diagnostics Inc.). Based on the hormonal estimations, female rats were divided into euthyroid and iodine-deficient groups (on LID). A total of eight female rats from the iodine-sufficient or euthyroid group and thirty-two female rats from the LID group were mated with normal male Sprague-Dawley rats in a female:male ratio of 2:1. Further, the LID group was divided into four subgroups having eight female rats in each group. Vaginal smears and microscopic visualisation of spermatozoa confirmed the embryonic day zero of the four subgroups: (1) LID, (2) LID + KI, (3) LID $+n-3$ FA and (4) $\mathrm{LID}+\mathrm{KI}+n-3$ FA. The diet of the $n-3$ FA group was supplemented with $300 \mathrm{mg}$ of $n$ - 3 FA contained in MAXEPA (Merck India Limited) daily through oral administration. $\mathrm{KI}$ was added in amounts that provided $10 \mu \mathrm{g}$ of iodine $/ 20 \mathrm{~g}$ of diet. The litter size for the euthyroid and LID groups did not differ significantly and were found to be $7 \pm 1$.

The dams and pups were kept under the aforementioned conditions and the cerebellum was dissected at postnatal day (P) 16 ( $n$ 15). All animal procedures performed earlier were approved by the institutional animal ethics committee as per the international guidelines for animal care and research.

\section{Lipid extraction from cerebellum and cerebellar fatty acid composition}

For lipid extraction ${ }^{(14)}$, for every group, the cerebella of three randomly selected pups born to different dams of each group 
were harvested at P16. A measure of $300 \mathrm{mg}$ of cerebellar tissue was homogenised in chloroform-methanol $(1: 2, \mathrm{v} / \mathrm{v})$ five times, followed by twice in chloroform-methanol $(2: 1$, $\mathrm{v} / \mathrm{v})$. Butylated hydroxytoluene (0.5\%; Sigma) was added to the chloroform-methanol solvent mixture to avoid oxidation of the extracted lipid. The homogenate was filtered and the filtrate was washed with 5-fold of its volume of water and left for layer separation. A biphasic system was obtained, and the lower layer mainly containing the tissue lipids was evaporated in a stream of $\mathrm{N}_{2}$. In brief, the oil/lipid was dissolved in $0 \cdot 1 \mathrm{M}$-alcoholic $\mathrm{KOH}$, refluxed in a water-bath for $15 \mathrm{~min}$ and treated with $0 \cdot 1 \mathrm{M}-\mathrm{HCl}$. This was then extracted with petroleum diethyl ether, followed by its evaporation in a stream of $\mathrm{N}_{2} \cdot \mathrm{BF}_{3}$-methanol was further added, refluxed for 2 min, followed by extraction with petroleum diethyl ether (40-60 ${ }^{\circ} \mathrm{C}$ boiling range). The petroleum diethyl ether was further evaporated in $\mathrm{N}_{2}$ and an aliquot of the FAmethyl ester extract was injected in a GC-MS, equipped with a PerkinElmer auto system XL gas chromatograph interfaced with a Turbomass mass spectrometric mass selective detector (PerkinElmer Inc.). The analytical column connected to the system was an ELITE-Wax capillary column (30 $\mathrm{m} \times 0.25 \mathrm{~mm}$ internal diameter, $0.5 \mathrm{~mm}$ film thickness). Helium was used as a carrier gas, with a flow rate of $1 \mathrm{ml}$ / min. The column temperature programme was $100^{\circ} \mathrm{C}$ $(0 \mathrm{~min}) ; 100-180^{\circ} \mathrm{C}$ at $68^{\circ} \mathrm{C} / \mathrm{min}$ (holding time: $0 \mathrm{~min}$ ); and $180-250^{\circ} \mathrm{C}$ at $10^{\circ} \mathrm{C} / \mathrm{min}$ (holding time: $15 \mathrm{~min}$ ). The transfer line and ion source temperatures were maintained at 200 and $250^{\circ} \mathrm{C}$, respectively. A solvent delay of $5 \mathrm{~min}$ was selected. In the full-scan mode, electron ionisation mass spectra in the range of $50-500 \mathrm{~m} / z$ were recorded at electron energy of $70 \mathrm{eV}$. In order to identify the FA in rat brain, the mass spectra of FA-methyl esters were compared with those of the National Institute of Standards and Technology library available in the instrument. Retention time of FA-methyl ester standards of FA (Sigma) was taken into consideration for quantification in selected ion monitoring by GC-MS. Values are expressed as parts per million.

\section{Measurement of enzymatic activity}

Catalase activity was measured according to the method described by Aebi ${ }^{(15)}$, following the decrease in absorbance of $\mathrm{H}_{2} \mathrm{O}_{2}$ at $240 \mathrm{~nm}$ and expressed as nKat $/ \mathrm{mg}$ protein. A measure of 1 nKat of catalase is defined as the amount of enzyme able to catalyse the degradation of $1 \mathrm{nmol}$ of $\mathrm{H}_{2} \mathrm{O}_{2} / \mathrm{s}$. Superoxide dismutase activity was measured according to the modified nitrite method and expressed as units/mg protein, where 1 unit of enzyme activity is defined as the amount of enzyme able to inhibit $50 \%$ of nitrite formation under assay conditions ${ }^{(16)}$. Malondialdehyde (MDA) was determined by quantifying the reaction product with thiobarbituric acid in the tissue supernatant ${ }^{(17)}$. The coloured end product was read at $540 \mathrm{~nm}$. The results were expressed as nmol $\mathrm{MDA} / \mathrm{mg}$ protein. Reduced glutathione reductase (GSH) was measured in the tissue supernatant using dithiobis-2-nitrobenzoic acid reagent ${ }^{(18)}$. The coloured end product was read at $412 \mathrm{~nm}$ and the results were expressed as $\mathrm{mg} \mathrm{GSH} / \mathrm{mg}$ protein.

\section{Terminal transferase dUTP nick end labelling assay}

Apoptosis was visualised in cerebellar sections of 16-d-old pups from both control and rats treated by various modalities following the instructions of the in situ apoptosis detection kit (Roche diagnostic, catalogue no. 11684809910). Apoptosis was quantified by counting the number of TUNEL-positive nuclei per 500 cells in a total of fifteen randomly chosen fields contained in three different sections. Labelling index was taken as the number of TUNEL-positive cells per total number of cells counted per field. Adjacent sections were processed as negative controls and run by omitting terminal deoxynucleotidal transferase (TdT) enzyme following identical procedure to confirm specificity of labelling. Positive controls were treated with nuclease enzyme supplied in the kit and then stained to confirm proper labelling. TUNEL-positive cells are expressed as means with their standard errors of three animals.

\section{Protein extraction and Western blotting}

Cerebellum samples taken at P16 ( $n$ 5) from three different litters (from all groups; euthyroid, hypothyroxinaemic and three reversibility groups) were harvested, snap-frozen in liquid $\mathrm{N}_{2}$ and stored at $-80^{\circ} \mathrm{C}$ until further investigation. For preparation of tissue homogenates, cerebellum samples were washed once with PBS and suspended in ten volumes of lysis buffer (10 mm-Tris-Cl (pH 7.5), $50 \mathrm{mm-NaCl}$, $1 \%$ Triton-X-100 containing phenylmethylsulphonyl fluoride (1 mm) and protease inhibitor cocktail (a mixture of 4-(2-aminoethyl) benzenesulphonyl fluoride, pepstatin A, E-64, bestatin, leupeptin and aprotinin); Sigma) and kept on ice for $10 \mathrm{~min}$. Tissues were then homogenised using a Teflon homogeniser, centrifuged at $12000 \mathrm{~g}$ for $15 \mathrm{~min}$ at $4^{\circ} \mathrm{C}$ and the supernatant was collected. Protein concentration was determined in supernatant using a protein assay kit (Bio-Rad). A measure of $50 \mu \mathrm{g}$ protein homogenate from the respective experimental groups was subjected to SDS-PAGE and electrotransferred onto nitrocellulose membrane. The membranes were incubated with either anti-caspase-3 or anti- $\beta$ actin (Cell Signalling Technology) antibody followed by incubation with horseradish peroxidase-conjugated secondary antibodies (Santa Cruz Biotechnology). The signals were detected using an enhanced chemiluminescence detection system (Amersham Biosciences). Relative expression of each protein was determined by densitometric analysis using LabWorks 4.0 software (UVP Limited).

\section{RNA extraction and real-time $P C R$}

Total mRNA was isolated from the cerebral cortex at P16 ( $n$ 4) from three different litters from three groups following a single-step mRNA isolation method using TRI reagent (MRC, Inc.). Total mRNA $(2 \mu \mathrm{g})$ was reverse transcribed to complementary DNA using Thermoscript RT-PCR kit (Invitrogen) following the manufacturer's instructions. Real-time analysis for neurotrophin-3 (NT-3), nerve growth factor (NGF), brainderived neurotrophic factor (BDNF), ROR $\alpha, \mathrm{p} 75 \mathrm{NTR}, \mathrm{TR} \alpha$, TR $\beta$, ROR $\alpha$, B-cell lymphoma-2 (Bcl-2) associated death 
promotor (BAD) and normalising gene glyceraldehyde-3-phosphate dehydrogenase $(G A P D H)$ was performed using specific Taqman UNIVERSAL PCR MASTER mix (Applied Biosystems) for assays on demand for gene accession numbers (Rn 01199 850-m1 (NT-3), Rn01533872-m1 (NGF), Rn00560868m1 (BDNF), Rn00562044-m1 (p75NTR), Rn00 579692-m1 (TR $\alpha)$, Rn00562044-m1 (TR $\beta)$ and Rn00576699-m1 (GAPDH)) or using SYBER GREEN MASTER mix (Applied Biosystems) for $R O R \alpha$, (forward: 5'-CCCAACCGTGTCCATGGCGG-3', reverse: $5^{\prime}$-CCCGTCGATGCGTTTGGCGA-3') and BAD (forward: 5'-CAGTGATCTGCTCCACATTC-3', reverse: 5'-TCCAGCTAGGATGATAGGAC- $3^{\prime}$ ), as per the manufacturer's instruction (Applied Biosystems), and fold changes in gene expression were calculated using the $2^{-\Delta \Delta C_{\mathrm{T}}}$ method.

\section{Immunofluorescence}

At P16, three pups, each from three separate litters, were taken from all the groups. Pups were anaesthetised and transcardially perfused with normal saline $(0.9 \% \mathrm{NaCl}(\mathrm{w} / \mathrm{v})$, $15-20 \mathrm{ml}$ for pups) followed by $4 \%(\mathrm{w} / \mathrm{v})$ paraformaldehyde in $0 \cdot 1 \mathrm{M}$-phosphate buffer $(20-25 \mathrm{ml})$ and post-fixed in $4 \%$ paraformaldehyde at $4^{\circ} \mathrm{C}$ for $4 \mathrm{~h}$. Tissues were then dehydrated in an alcohol series for paraffin embedding by a standard protocol. Coronal sections $(3 \mu \mathrm{m})$ were cut from the rat brain containing the cerebellum from the pups at P16 developmental stages and mounted on poly-L-lysine-coated slides. De-paraffinised and rehydrated coronal sections were boiled in a microwave oven using $10 \mathrm{~mm}$-citrate buffer $(\mathrm{pH}$ 6.0) for antigen retrieval. Sections were blocked with $10 \%$ normal sheep serum for $20 \mathrm{~min}$. To localise the Purkinje neurons, sections were stained with antibodies against calbindin D28K (1:250; Cell Signaling Technology) overnight at $4^{\circ} \mathrm{C}$. After washing with PBS, the sections were incubated with anti-mouse Alexa Flor 546 (Invitrogen) secondary antibodies for $1 \mathrm{~h}$ in the dark. The sections were then counterstained with Hoechst 33258 (Invitrogen) and visualised under a Nikon 80i fluorescence microscope (Nikon Instruments Inc.). Image-Pro plus 5.1 software (Media Cybernetics, Inc.) was used for image capturing and cell counting.

\section{Neurobehavioural testing}

A total of eight pups born to each group of rats were weaned away on P24. Care was taken to include equal numbers of male and female pups. Male and female pups were housed in separate cages. As the litters were born on different days to different mothers belonging to different groups, a date of birth record was maintained to know the exact date when these pups achieved P24. During the post-weaning period, these pups were fed with an iodine-sufficient control diet fortified with maize oil until $\mathrm{P} 40$. These pups were administered training for two consecutive days starting from P38, before performing the final test on $\mathrm{P} 40$. All the three tests were carried out on pups that achieved $\mathrm{P} 40$ on a particular day. The following neurobehavioural tests were carried out on these pups.

\section{Motor coordination test}

This was performed in rat pups from different dietary supplement groups at the age of $\mathrm{P} 40$. Rats were trained three times a day for two consecutive days on a rotarod at a constant speed of $20 \mathrm{rpm}$. On the $3 \mathrm{rd}$ day, the time of stay was recorded for different rats on the rotating rod. The length of time that a given animal stays on this rotating rod was a measure of their balance, coordination, physical condition and motor planning. The mean index value of the three trials was used to reflect the motor coordination functions of each rat.

\section{Y-maze test}

The Y-maze was performed as described previously ${ }^{(19)}$. During the Y-maze test, $\mathrm{P} 40$ rats were placed in the centre of a symmetrical Y maze and were allowed to explore freely in the maze for $8 \mathrm{~min}$. The total number and sequence of arms entered were recorded. An arm was entered if the hind paws of the rat were completely in the arm. The rats were trained for two consecutive days to habituate. On day 3, the alteration between arms was recorded. Rats that found the arm having a light on, indicating absence of current in that arm, within $30 \mathrm{~s}$ were recorded as having a positive response. The acquisition time was recorded to determine short-term memory. The mean value of the three trials was used to reflect the short-term memory functions of each rat.

\section{Morris water maze test}

The ability of different groups of rat pups to learn and memorise was tested by a Morris water maze (Techno India Pvt Ltd) ${ }^{(20)}$. The water maze consisted of a large, circular, galvanised steel pool. A white platform $(10 \mathrm{~cm}$ in diameter) was placed inside and the tank was filled with water until the top of the platform was submerged $1 \mathrm{~cm}$ below the water's surface. A sufficient amount of white paint was added to make the water opaque and render the platform invisible. In addition to the visual cues, on the walls of the laboratory (shapes), five sheets of paper with black-and-white geometric designs attached to the sides of the tank served as additional cues. An automated tracking system was used to analyse the swim path of each subject and it calculated the escape latencies and total path lengths. Beginning on the following day, rats were given seven acquisition sessions that consisted of four trials per $\mathrm{d}$, with an inter-trial interval of $10 \mathrm{~min}$ throughout the course of this acquisition period. The hidden platform remained in the same fixed position for all rats. Once a rat located the platform, it was allowed to remain there for $30 \mathrm{~s}$ before being removed from the tank. The automated tracking system recorded the path length, the escape latency and swimming speed to find the platform, and these data were given by the computer as the index of learning and memory. Mean latency of each session was obtained for the purpose of data representation.

\section{Statistical analysis}

Data are presented as means with their standard errors of the indicated number of experiments. Statistical analysis was 
Table 1. Circulating thyroid hormone levels in dams (Mean values with their standard errors, $n 5$ in each group)

\begin{tabular}{lccccc}
\hline & \multicolumn{2}{c}{ Control } & & \multicolumn{2}{c}{ LID } \\
\cline { 2 - 3 } \cline { 6 - 6 } \cline { 6 - 6 } & Mean & SEM & & Mean & SEM \\
\hline T3 $(\mathrm{nmol} / \mathrm{l})$ & 1.09 & 0.18 & & $1 \cdot 11$ & 0.29 \\
T4 $(\mathrm{nmol} / \mathrm{l})$ & $63^{\star *}$ & $5 \cdot 1$ & & 14.2 & 3.3 \\
FT4 $(\mathrm{pmol} / \mathrm{l})$ & $19 \cdot 23$ & 4.4 & & $1 \cdot 13$ & 0.41 \\
\hline
\end{tabular}

LID, low-iodine diet; T3, triiodothyronine; T4, thyroxine; FT4, free T4.

** Mean value was significantly different compared with LID $(P<0.005)$

performed using SPSS 9.0 software (SPSS, Inc.). Data were analysed by one-way ANOVA, followed by the Bonferroni post hoc test. $P<0.05$ was taken to indicate a statistically significant difference. The significance levels of multiple comparisons are given in Table S1 (available online).

\section{Results}

We compared the pups born to iodine-sufficient (control) and LID-fed rat dams. This diet regimen was continued for 3 months prior to conception. From P1, iodine-deficient dams along with their litter were either continued on the same or LID diet given along with KI or $n-3$ FA alone or both KI and $n$ - 3 FA combined together. Half the number of pups were continued on the same diet regimen and tested for their motor coordination and neurobehavioural parameters. After recording body weights, circulating levels of T3, T4 and FT4 were estimated in equal numbers of pups from each dam on the peak cerebellar neurogenesis period of day 16. Pups were then killed for assessment of cerebellar morphology and markers of apoptosis and oxidative stress, as well as neurotrophins, nuclear TR and ROR.

The body weight and hair texture in $16 \mathrm{~d}$ pups remained unaltered in all the groups of pups (data not shown). Serum T4 and FT4 levels were significantly decreased in pups on LID compared with the controls. T3 levels, though, showed a decreasing trend, but the decrease was not significant compared with the controls (Table 1). Circulating FT4 and T3 levels normalised in KI-supplemented groups compared with controls, but total T4 levels, though significantly improved, failed to normalise compared with controls. Circulating FT4, total serum $\mathrm{T} 4$ and $\mathrm{T} 3$ levels remained significantly low in iodine-deficient rat pups fed on $n-3$ FA supplementation alone compared with controls (Table 2).

\section{n-3 Fatty acid treatment elevates developing cerebellar n-3 fatty acid (DHA) levels}

We measured the levels of $n-3$ FA by GC-MS in the cerebellar tissue of P16 pups from all the groups. Results showed that $n$-3 FA-treated pups showed significant increases in levels of $n$-3 FA compared with the control, LID and KI alonesupplemented groups. The levels of DHA in cerebellar tissue rose by 6.5 -fold in $n$-3 FA $(P<0.001)$ and by 7 -fold in $n-3$ $\mathrm{FA}+\mathrm{KI}(P<0 \cdot 001)$ supplemented groups when compared with the control. Thus, treatment of iodine-deficient dams with $n$-3 FA caused elevations in cerebellar $n$ - 3 FA composition in the P16 offspring (Table 3).

\section{Improvement in motor coordination and cognitive performance}

We observed significant worsening of motor coordination and memory at $\mathrm{P} 40$ in iodine-deficient rat pups, when compared with the euthyroid group pups $(P<0 \cdot 005)$. We did not observe significant improvement in motor coordination, at $\mathrm{P} 40$, in iodine-deficient rat pups that were supplemented with KI alone. However, significant improvement in motor coordination was observed in rat pups supplemented with $n$-3 FA alone as well as in those co-supplemented with KI groups at day 40 when compared with the LID group pups $(P<0.05)$ (Fig. 1(a)-(c)). The significant memory improvement was seen in all the treatment groups when compared with iodine-deficient pups $(P<0.005)$ (Fig. 1(a)-(c)).

\section{Rescue of impaired dendrite arborisation}

Calbindin D28K staining at P16 revealed gross stunting of dendrites in iodine-deficient cerebellums compared with controls (Fig. 2(a) and (b)). Both iodine and n-3 FA supplementation alone did significantly improve the dendrite architecture, but their effect was further enhanced under combinatorial supplementation of iodine and $n$-3 FA (Fig. 2(b) $v$. Fig. 2(c) and (d)). The maximal restoration of dendrite arborisation of Purkinje neurons was seen in combinatorial supplement given to pups (Fig. 2(b) v. Fig. 2(e)).

\section{Alterations in cerebellar apoptosis}

The present result showed significantly increased TUNEL-positive cells in iodine-deficient cerebellum compared with controls $(P<0 \cdot 005)$ (Fig. 3(a) and (b)), indicating

Table 2. Circulating thyroid hormone levels in pups of different dietary groups at postnatal day 16

(Mean values with their standard errors; $n 5$ in each group)

\begin{tabular}{|c|c|c|c|c|c|c|c|c|c|c|}
\hline & \multicolumn{2}{|c|}{ Control } & \multicolumn{2}{|c|}{ LID } & \multicolumn{2}{|c|}{$\mathrm{LID}+\mathrm{KI}$} & \multicolumn{2}{|c|}{ LID $+n-3$ FA } & \multicolumn{2}{|c|}{$\mathrm{LID}+\mathrm{KI}+n-3 \mathrm{FA}$} \\
\hline & Mean & SEM & Mean & SEM & Mean & SEM & Mean & SEM & Mean & SEM \\
\hline T3 (nmol/l) & $1 \cdot 21$ & 0.15 & 0.87 & 0.054 & 1.06 & 0.05 & 0.78 & 0.09 & $1 \cdot 15$ & 0.05 \\
\hline T4 (nmol/l) & $77 \cdot 27^{\star \star}$ & $3 \cdot 37$ & $18 \cdot 08$ & $2 \cdot 32$ & $58 \cdot 38^{\star \star}$ & $7 \cdot 23$ & $19 \cdot 66$ & 2.08 & $55 \cdot 98^{\star *}$ & $8 \cdot 27$ \\
\hline FT4 pmol/l & 14.97 & 0.15 & $4 \cdot 36$ & 0.42 & $14 \cdot 10$ & 0.45 & 4.44 & 0.49 & $14 \cdot 27$ & 0.3 \\
\hline
\end{tabular}

LID, low-iodine diet; KI, potassium iodide; FA, fatty acid; T3, triiodothyronine; T4, thyroxine; FT4, free T4.

${ }^{\star *}$ Mean value was significantly different compared with LID $(P<0.005)$. 
Table 3. Levels of DHA in cerebellar tissue from three pups each of both the sexes from all the groups of rats

(Mean values and standard deviations)

\begin{tabular}{|c|c|c|c|}
\hline \multirow[b]{2}{*}{ S. no. } & \multirow[b]{2}{*}{ Groups } & \multicolumn{2}{|c|}{$\begin{array}{l}\text { DHA in cerebellar } \\
\text { tissue (ppm) }\end{array}$} \\
\hline & & Mean & SD \\
\hline 01 & Euthyroid & 1.574 & 0.49 \\
\hline 02 & LID & 0.846 & 0.58 \\
\hline 03 & LID+KI & 0.889 & 0.02 \\
\hline 04 & LID+n-3 FA & $9 \cdot 896^{\star \star}+\dagger$ & 0.16 \\
\hline 05 & LID $+\mathrm{KI}+n-3 \mathrm{FA}$ & $10 \cdot 742^{\star \star}+\dagger$ & 0.41 \\
\hline
\end{tabular}

ppm, Parts per million; LID, low-iodine diet; KI, potassium iodide; FA, fatty acid.

** Mean value was significantly different compared with LID $(P<0.005)$

††Mean value was significantly different compared with control $(P<0.005)$.

enhanced apoptosis. There were significantly fewer TUNELpositive cells on supplementation, either with KI or $n-3$ FA $(P<0 \cdot 005)$. However, further reduction of TUNEL-positive cells was seen on combined supplementation when compared with KI and $n$ - 3 FA treatments alone $(P<0.005)$
(Fig. 3(a) and (b)). These results show an additive effect of combined treatment with KI and $n-3$ FA on the extent of apoptosis, comparable with the euthyroid control group pup cerebellum. Alterations in caspase-3 show a trend similar to that obtained for TUNEL, with significantly increased levels seen in the cerebellum of iodine-deficient pups compared with the controls, and significantly reduced levels seen on either KI or $n$-3 FA supplementation $(P<0.005)$, with combined supplementation showing further significant reduction compared with either of the individual supplements $(P<0.005)$ (Fig. 3(c)). Seen together, these results show significant enhancement of apoptosis caused by iodine deficiency and its mitigation by both $\mathrm{KI}$ and $n$ - 3 FA supplementation, with combined supplementation giving additive benefit.

Increased TUNEL positivity in iodine-deficient cerebellum was not reflected in $\mathrm{Bcl} 2$ and $\mathrm{Bcl}-2$ associated $\mathrm{X}$ protein (Bax) levels. They remained unaltered in iodine-deficient cerebellum compared with controls (NS) (data not shown). However, we observed significantly decreased BAD mRNA levels, which corroborated with lower levels of cleaved caspase-3 in $n$-3 FA-supplemented group and even more so in iodine plus $n$-3 FA co-supplemented groups $(P<0 \cdot 005)$ (Fig. 3(c) and $(\mathrm{d})$ ).

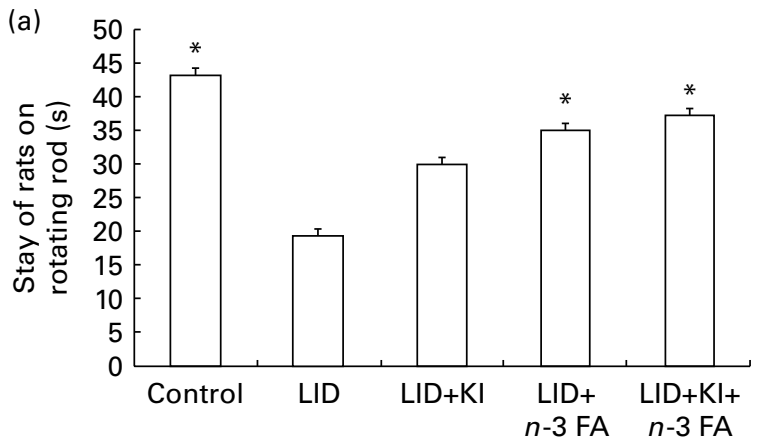

(b)

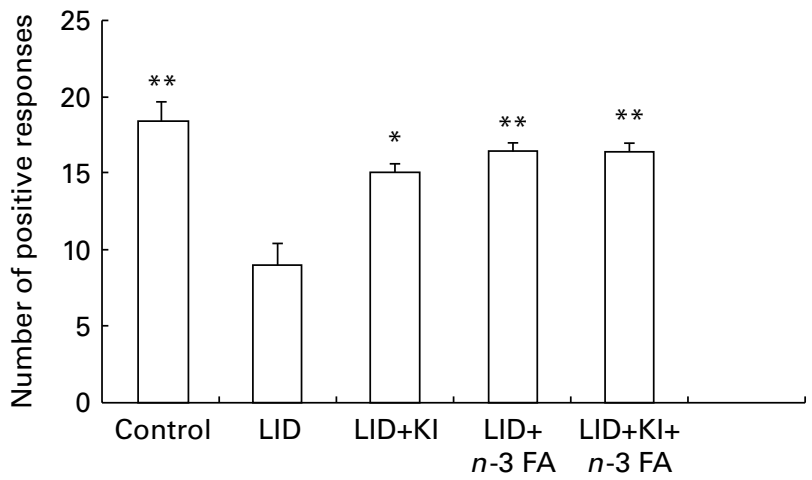

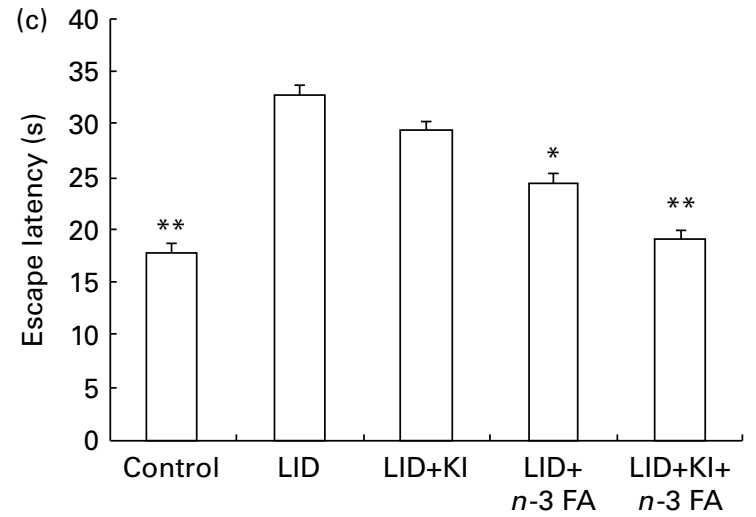

Fig. 1. Motor coordination and cognitive performance of different dietary groups at postnatal day (P) 40: control group; low-iodine diet (LID) group; LID + potassium iodide (KI) group; LID $+n-3$ fatty acid (FA) group; LID $+\mathrm{KI}+n-3 \mathrm{FA}$ group. Eight pups born to each group of rats were weaned away on P24. Care was taken to include equal numbers of male and female pups. Male and female pups were housed in separate cages. As the litters were born on different days to different mothers belonging to different groups, a date of birth record was maintained to know the exact date when these pups achieved P24. During the postweaning period, these pups were fed with an iodine-sufficient control diet fortified with maize oil until P40. These pups were administered training for two consecutive days starting from P38 before imparting the final test on P40. All the three tests were carried out in pups that achieve P40 on a particular day. Values are means, with their standard errors represented by vertical bars. (a) Motor co-ordination performance assessed as time of stay on rotating rod. (b) Y-maze test for learning performances assessed as number of positive responses. (c) Morris water test showing escape latency. Mean value was significantly different from that for the LID group: * $P<0.05,{ }^{\star *} P<0.005$. 


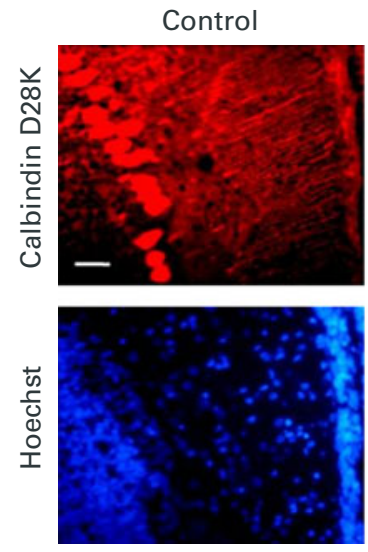

(a)
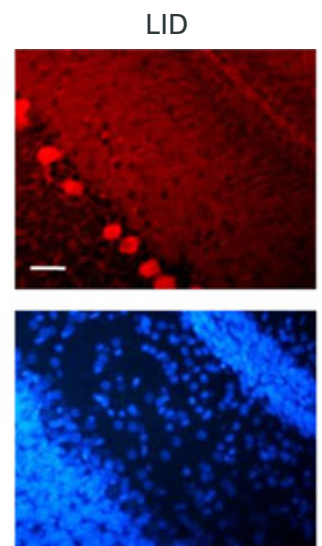

(b)

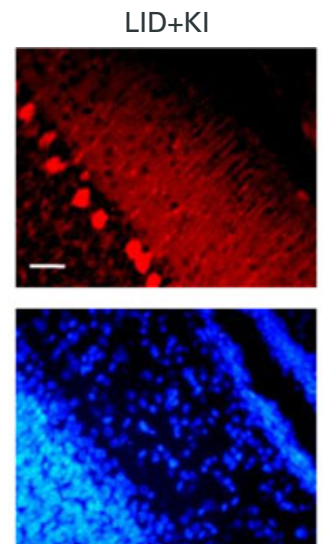

(c)
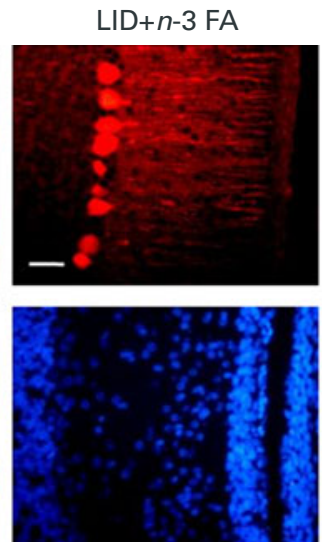

(d)
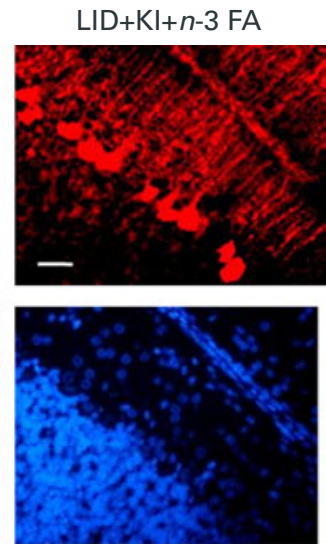

(e)

Fig. 2. Representative photomicrograph of calbindin D28K immunofluorescence staining showing Purkinje cells dendritic arborisation in cerebellum of different groups ((a) control; (b) low-iodine diet (LID); (c) LID+potassium iodide (KI); (d) LID+n-3 fatty acid (FA)) at postnatal day 16. Hoechst was used as a counternuclear stain. Scale bar $50 \mu \mathrm{m}$. (A colour version of this figure can be found online at http://www.journals.cambridge.org/bjn).

(a)
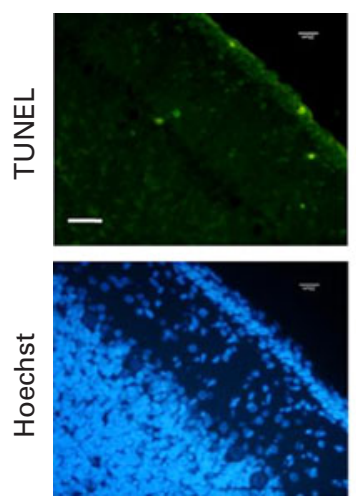

(b)

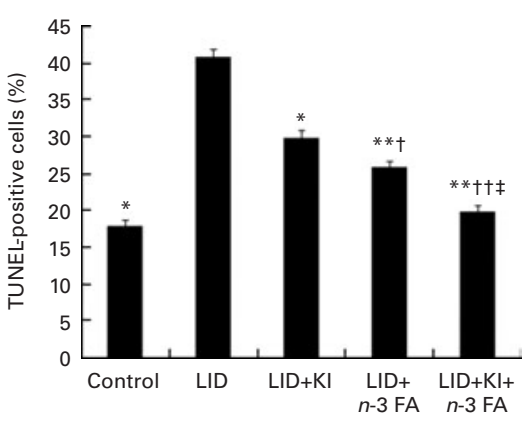

LID
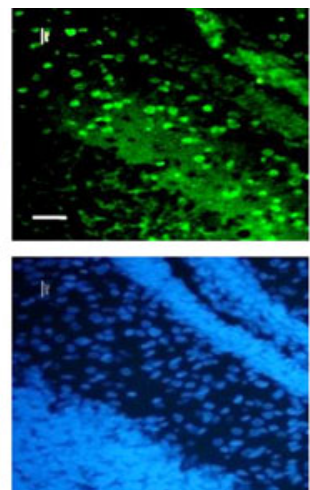

LID+KI
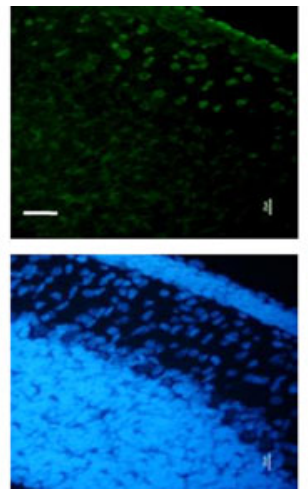

LID $+n-3$ FA
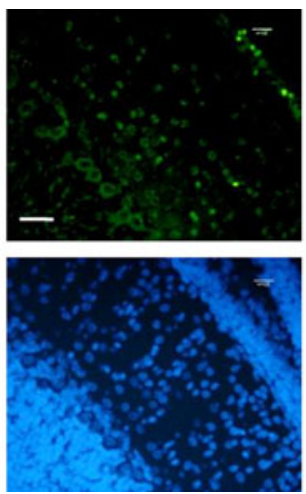

$\mathrm{LID}+\mathrm{KI}+n-3 \mathrm{FA}$
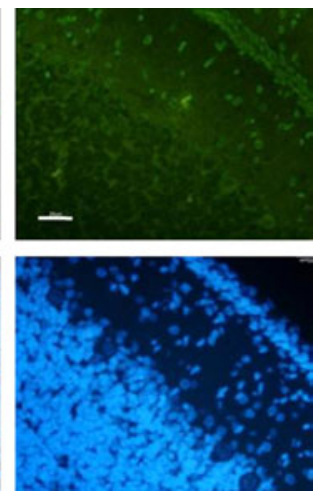

(c)

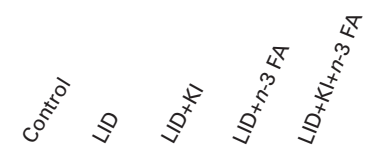

(d)
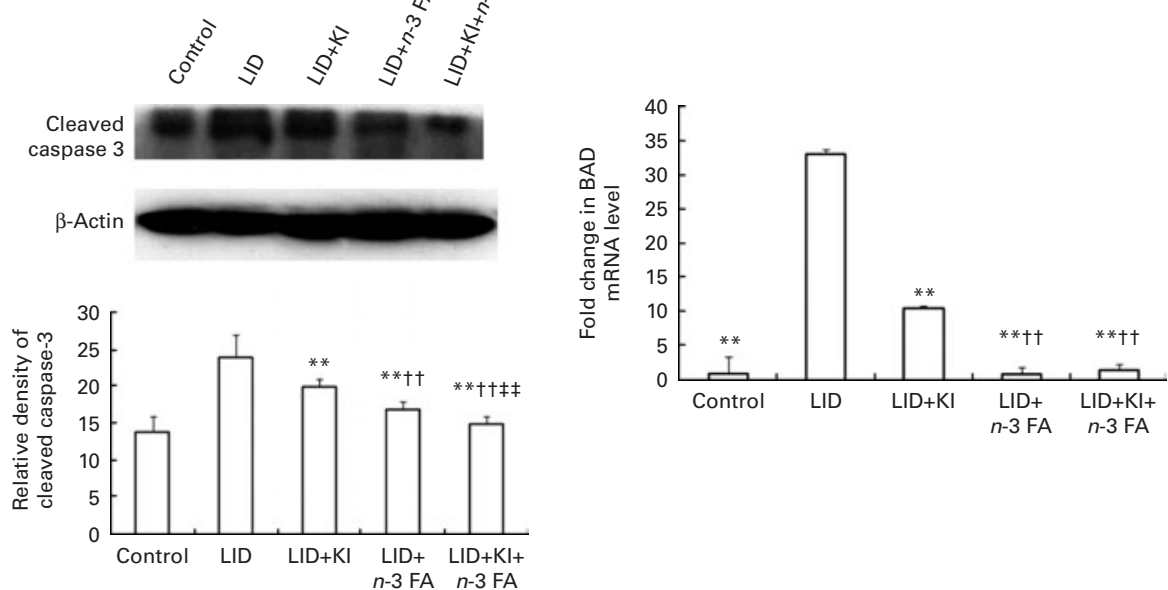

Fig. 3. Analysis of cell death in the developing cerebellum under different dietary regimens. (a) Representative photomicrographs of terminal transferase dUTP nick-end labelling (TUNEL)-labelled cells in the cerebellum at postnatal day (P) 16 in different groups: control group; low-iodine diet (LID) group; LID+potassium iodide (KI) group; LID $+n-3$ fatty acid (FA) group; LID $+\mathrm{KI}+n-3$ FA group. (b) The apoptotic index was expressed as percentage change in TUNEL-positive cells $/ 500$ nuclei (Hoechst stained). (c) Immunoblots of whole-cell lysate $(50 \mu \mathrm{g})$ prepared from cerebellum at P16 from different groups, showing levels of cleaved caspase-3 and $\beta$-actin. Histogram shows the relative densities of cleaved caspase-3 in different groups. (d) Histogram showing the transcriptional level changes in the expression of BAD in different groups at P16. Values are means of TUNEL-positive cells in different groups, with their standard errors represented by vertical bars. Mean value was significantly different from that for the LID group: ${ }^{\star} P<0.05,{ }^{* *} P<0.005$. Mean value was significantly different from that for the LID+KI group: $\dagger P<0.05$, $\dagger \uparrow P<0.005$. Mean value was significantly different from that for the LID $+n-3$ FA group: $\ddagger P<0.05$, $\ddagger \ddagger P<0.005$. (A colour version of this figure can be found online at http://www.journals.cambridge.org/bjn). 
(a)

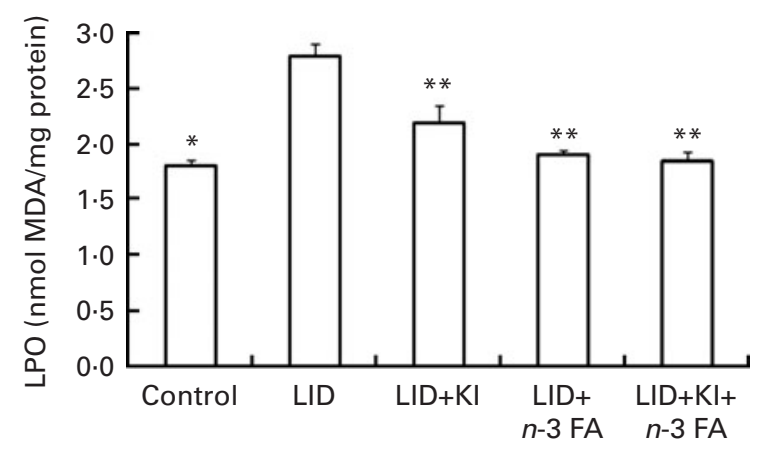

(c)

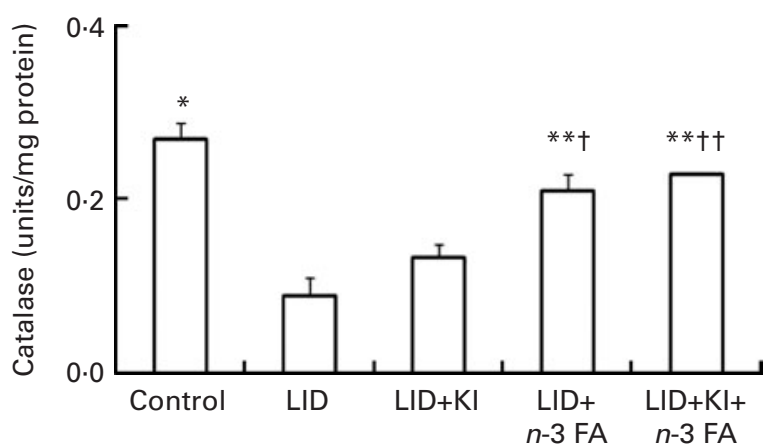

(b)

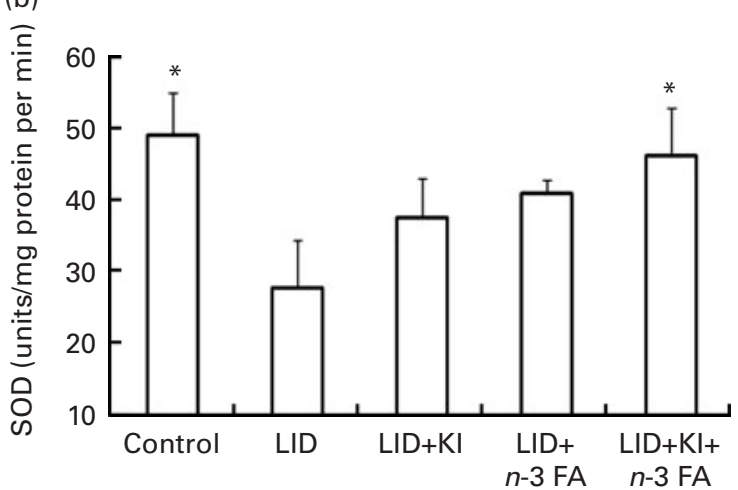

(d)

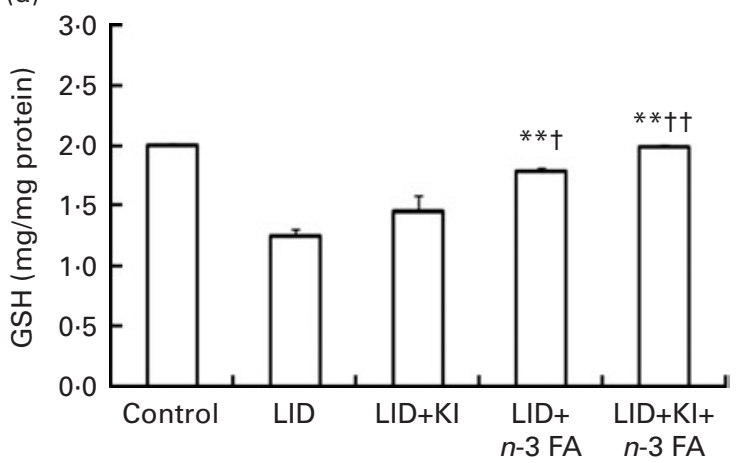

Fig. 4. Analysis of oxidative stress markers in the developing cerebellum under different dietary regimens. Changes in the patterns of (a) lipid peroxidation (LPO), (b) superoxide dismutase (SOD), (c) catalase and (D) glutathione reductase (GSH) levels in the different groups: control group; low-iodine diet (LID) group; LID + potassium iodide (KI) group; LID $+n-3$ fatty acid (FA) group; LID $+\mathrm{KI}+n-3 \mathrm{FA}$ group. Values are means of the different groups $(n 5)$, with their standard errors represented by vertical bars. Mean value was significantly different from that for the LID group: ${ }^{\star} P<0.05,{ }^{* \star} P<0.005$. Mean value was significantly different from that for the LID + KI group: $\dagger P<0.05$, $†+P<0.005$.

\section{Alteration in oxidative stress}

We found lipid peroxidation to be significantly increased in iodine-deficient pups compared with the controls $(P<0 \cdot 005)$ (Fig. 4(a)). Results also indicated significant loss of superoxide dismutase $(P<0.05)$, catalase and GSH activity in iodinedeficient rat pups compared with the controls $(P<0 \cdot 005)$. KI treatment of LID rats alone did not improve levels of catalase, GSH or superoxide dismutase; however, it resulted in improved lipid peroxidation $(P<0 \cdot 005)$. While superoxide dismutase levels did not show any improvement on treatment with $n$-3 FA alone, they showed significant improvement upon combined $n-3 \mathrm{FA}$ and KI treatment $(P<0.05)$ A significant improvement in the levels of catalase and GSH activity was observed in supplementation groups receiving either $n$ 3 FA alone or those receiving it along with KI compared with LID $(P<0 \cdot 005)$. However, combined supplementation of KI and $n$ - 3 FA did not produce any further improvement compared with $n$-3 FA alone supplementation (Fig. 4(b)-(d)).

\section{Changes in cerebellar neurotrophins}

$\mathrm{TH}$ is known to regulate the expression of neurotrophins in developing rat cerebellum. mRNA expression of NT-3, BDNF and low-affinity NGF revealed a mixed response to iodine deficiency and supplementation or $n-3$ FA and iodine
(Fig. 5(a)-(c)). While cerebellar mRNA expression of NT-3 and BDNF in iodine-deficient pups significantly decreased $(P<0 \cdot 005)$, expression levels significantly increased for both NGF $(P<0.005)$ and p75NTR $(P<0.001)$ when compared with controls. Iodine supplementation alone failed to restore levels of both NT-3 and BDNF, but $n-3$ FA supplementation either alone or in combination with KI, completely restored NT-3 levels to control levels (Fig. 5(b)). In case of BDNF, optimisation of mRNA levels was only observed under combinatorial supplementation of iodine and $n-3$ FA $(P<0.005)$ (Fig. 5(a)). Increased mRNA levels of NGF and p75NTR seen under the iodine-deficient condition responded differently to iodine and $n$-3 FA supplements. p75NTR, which was upregulated under iodine deficiency, showed a significant decrease on supplementation with iodine or $n-3 \mathrm{FA}$ and was further significantly enhanced on combined supplementation $(P<0.005)$ (Fig. 5(d)). In contrast, NGF normalised only on iodine supplementation $(P<0.005)$ and remained high when supplemented with either $n-3 \mathrm{FA}$ alone or given in combination with iodine (Fig. 5(c)).

\section{Circulating thyroid hormone levels and thyroid hormone receptor expression}

We saw improvement, albeit to a different degree, in several functional, morphological as well as biochemical parameters 

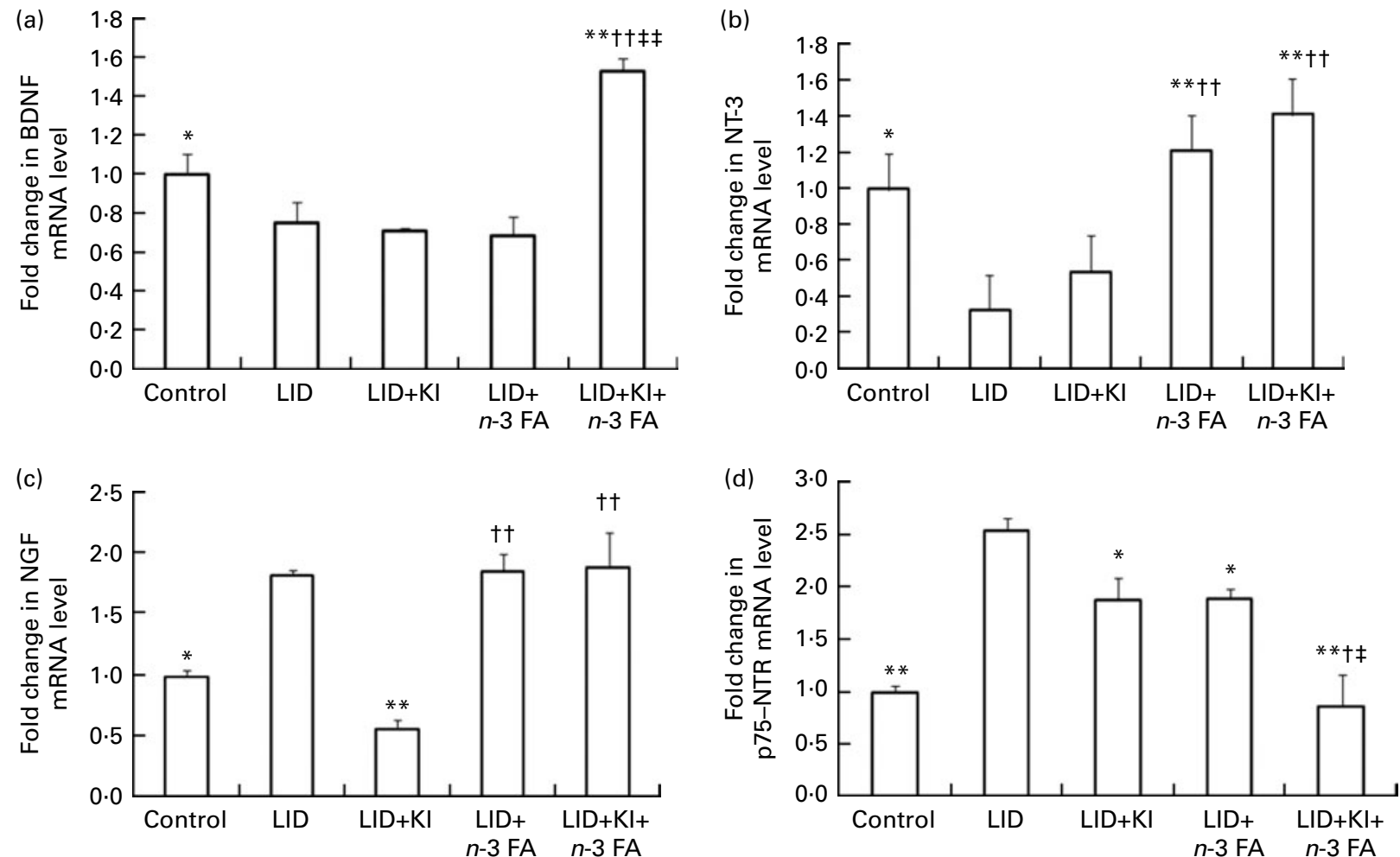

Fig. 5. Levels (fold changes) of neurotrophins and their receptor under different dietary regimens. Graph showing the transcriptional level changes in the expression of neurotrophins and their receptors in different groups at postnatal day 16: control group; low-iodine diet (LID) group; LID + potassium iodide (KI) group; LID $+n-3$ fatty acid (FA) group; LID $+\mathrm{KI}+n-3 \mathrm{FA}$ group. (a) Brain-derived neurotrophic factor (BDNF), (b) neurotrophin-3 (NT-3), (c) nerve growth factor (NGF) and (d) p75 neurotrophin receptor (p75NTR). Glyceraldehyde-3-phosphate dehydrogenase mRNA was used as an internal control. Values are means ( $n$ 5), with their standard errors represented by vertical bars. Mean value was significantly different from that for the LID group: ${ }^{*} P<0.05,{ }^{\star *} P<0.005$. Mean value was significantly different from that for the LID $+\mathrm{KI}$ group: $\dagger P<0.05$, $† \dagger P<0.005$. Mean value was significantly different from that for the LID+ $n-3 \mathrm{FA}$ group: $\ddagger P<0.05$, 㧊P<0.005.

related to cell death and oxidative stress, either by supplementation of iodine and/or $n-3 \mathrm{FA}$ alone. Though the improvement with the $n$-3 FA-only treatment, without enhancement of circulating TH levels, was a bit puzzling, the rescue effect of combined supplementation was ubiquitous. Analysis of TR was done with quantitative PCR and caution is exercised in interpretation of the results. Under the iodine-deficient condition, a significant up-regulation of TR $\beta$ ( $>1.5$-fold, $P<0.005)$ was observed compared with the control group. This was concomitant with a highly significant decrease in the levels of TR $\alpha$ ((>3-fold, $P<0.005)$ Fig. 6(a) and (b)). Another TH-dependent gene $R O R \alpha$, which is partially responsible for the regulation of neurotrophic action on Purkinje cells' dendrites, was also analysed. ROR $\alpha$ levels were significantly low under iodine deficiency compared with the control group ( $>4$-fold, $P<0.005$ ) and showed moderate, yet, significant recovery with either treatment regimen (Fig. 6(c)). n-3 FA supplementation, either alone or in combination with iodine supplementation, restored the levels of TR to euthyroid levels. This restoration was much more significant in the case of TR $\alpha$ and $\operatorname{ROR} \alpha$ on the combined treatment with KI plus $n$-3 FA supplementation ( $>$ 2-fold, $P<0 \cdot 005$ ). However, when supplemented together with both nutrients, recovery in $\mathrm{ROR} \alpha$ levels was significant, although still less than control $(P<0 \cdot 005)$.

\section{Discussion}

Iodine deficiency is known to produce a hypothyroxinaemic state, which is 150-200 times more common than hypothyroidism $^{(1)}$. It is known that postnatal iodine supplementation to dams improves motor coordination and cognition ability in progeny of iodine-deficient rats through recovery of neuronal architecture of the developing cortex and cerebellum. The present study was planned to investigate if any additional improvement is achievable in functional and morphological attributes on supplementation of $n-3$ FA along with iodine. The broad findings of the present study include the following: (1) several-fold increase in $n$-3 FA uptake was found in the cerebellum on $n$-3 FA supplementation, (2) KI supplementation alone, though effective in improving learning and memory function, fails to improve motor coordination; however, supplementation of $n-3$ FA alone as well as along with KI improves both motor coordination and memory function and (3) maximal restoration of dendrite arborisation, significant reduction of cerebellar apoptosis and significantly reduced oxidative stress observed on combined supplementation of $n-3$ FA and KI suggest additional benefits derived by cerebellum undergoing iodine deficiency insult on either $n$-3 FA supplementation alone or with iodine.

Numerous basic and clinical studies have shown the benefits of $n-3$ FA in the well-being of mental health ${ }^{(21)}$. 

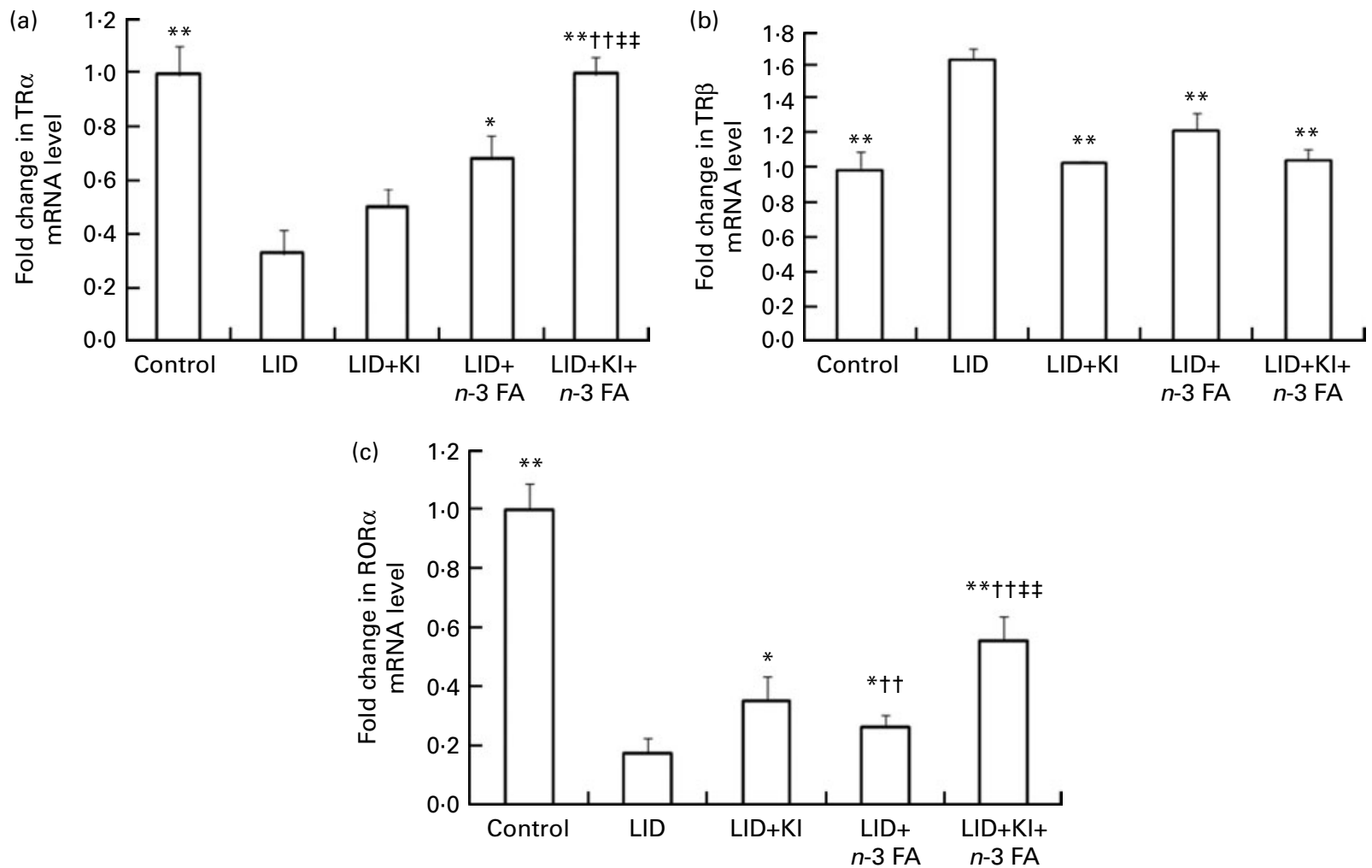

Fig. 6. mRNA levels (fold changes) of thyroid hormone receptor (TR) $\alpha(a), \operatorname{TR} \beta$ (b) and retinoic orphan receptor (ROR) $\alpha$ (c) in the developing cerebellum of different dietary groups at postnatal day 16: control group; low-iodine diet (LID) group; LID+potassium iodide (KI) group; LID+ $n-3$ fatty acid (FA) group; LID+KI + $n-3$ FA group. Glyceraldehyde-3-phosphate dehydrogenase mRNA was used as an internal control. Values are means $(n 5)$, with standard errors represented by vertical bars. Mean value was significantly different from that for the LID group: ${ }^{\star} P<0.05,{ }^{\star *} P<0.005$. $\dagger \dagger$ Mean value was significantly different from that for the $\mathrm{LID}+\mathrm{KI}$ group $(P<0.005)$. $\ddagger \ddagger$ Mean value was significantly different from that for the LID $+n-3 \mathrm{FA}$ group $(P<0.005)$.

$n$-3 FA provide benefits by exerting a protective mechanism at the cellular and neuronal levels, including modulation of the inflammatory cascade following traumatic brain injury ${ }^{(22,23)}$. This protective signalling is already well-established in a number of neurodegenerative disorders like Alzheimer's and Parkinson's disease ${ }^{(9)}$. However, apart from their role in neuroprotection of the adult brain ${ }^{(24)}$, relatively little is known of their action in disorders of the developing brain ${ }^{(25-27)}$. Epidemiological studies are now providing favourable evidence for the nutritional benefit of early $n$-3 FA supplementation in children ${ }^{(28-30)}$. Although the effects of $n$-3 FA on the developing brain in a chemically induced hypothyroid model have been studied earlier ${ }^{(8)}$, we in the present study tested the ability of $n-3$ FA in protecting the developing brain from the deleterious effect of nutritional iodine deficiency. Iodine deficiency, which results in low levels of $\mathrm{TH}$ in the developing brain, causes a multitude of neurological disorders in human populations and poses a serious threat to public health. We here found that $n$-3 FA supplementation to iodine-deficient rat pups, either alone or in combination with iodine, provided a remarkable recovery in both cellular and cognitive indices affected under iodine deficiency.

At the cellular level, iodine deficiency is associated with stunted dendritic architecture and increased apoptosis in the developing rat cerebellum ${ }^{(31)}$. The present results here clearly demonstrate the efficacy of $n-3$ FA in preventing these abnormalities, both alone and even better when combined with iodine. Mechanisms by which $n-3$ FA seem to prevent cellular injury under iodine deficiency involve regulation of pro-apoptotic $\mathrm{Bcl} 2$ member proteins, enforcing antioxidant response and increasing neurotrophic support. Interestingly though, we found some remarkable differences in the regulation of $\mathrm{Bcl} 2$ family proteins under our present model of iodine deficiency compared with chemically induced hypothyroidism. Although both anti-apoptotic $\mathrm{Bcl} 2$ and B-cell lymphoma extra large (BclxL) levels (data not shown) were unchanged under iodine deficiency, compared with that under chemically induced hypothyroidism ${ }^{(5)}$, pro-apoptotic BAD levels were significantly increased under iodine deficiency. The present results suggest that the protective action of $n-3$ FA in iodine deficiency could involve the down-regulation of pro-apoptotic $\mathrm{Bcl} 2$ proteins like $\mathrm{BAD}$ instead of affecting the anti-apoptotic family members like $\mathrm{Bcl} 2$. Other interesting finding was the up-regulation of antioxidant enzymes in $n$-3 FA+ iodine-treated iodine-deficient pups $^{(6)}$. $n$-3 FA have been previously shown to reduce oxidative stress and we here further corroborate it ${ }^{(32)}$.

Neurotrophic loss is considered as a major cause of impaired neurodevelopment under iodine deficiency. Neurotrophins like NT-3 and BDNF in the developing rat cerebellum are required for dendritic arborisation in Purkinje neurons and are essential for the survival of other neuronal subtypes ${ }^{(31)}$.

The present data showed that $n$-3-FA limit the impairment in neuronal morphology and survival by restoring the levels 
of NT-3 and BDNF, which are markedly reduced in iodine deficiency. We also found other genes, like $R O R \alpha$ and p75NTR ${ }^{(7)}$, which fine tune the development and patterning of rat cerebellum in response to neurotrophins, although not affected by $n-3$ FA and iodine supplementation alone, could be regulated when the iodine-deficient pups were co-supplemented with both the nutrients.

Other than these findings, we also report, for the first time, that TR expression itself can be affected by $n-3$ FA in the developing brain. Under iodine deficiency, $\mathrm{TR} \alpha$ levels are reduced with a compensatory increase in TR $\beta$ levels in vivo. Iodine, along with $n$ - 3 FA supplementation, is able to normalise TR $\alpha$ levels in the cerebellum, and it being the prominent receptor responsible of early neuronal development ${ }^{(33-35)}$, might probably explain its ability to reverse other cellular and behavioural deficits seen under iodine deficiency. Notwithstanding the significance levels arrived through post hoc ANOVA, in the iodine-deficient group, the increase in TR $\beta$ transcript was less than 2-fold (approximately 1.7-fold), while the decrease in $\operatorname{TR} \alpha$ and $\operatorname{ROR} \alpha$ transcripts was more than 3- to 4-fold when compared with controls. Results show that the iodine-deficient state reduces $\mathrm{TR} \alpha$ and $\mathrm{ROR} \alpha$ transcripts by many fold, which recover optimally upon combined supplementation of KI and $n-3$ FA. In contrast, the TR $\beta$ transcript withstands iodine deficiency and remains constitutively expressed to the similar level compared with control on various supplementation regimens. It has been previously shown that the absence of $\mathrm{TR} \alpha$ receptors in wild-type mice leads to hypothyroxinaemia ${ }^{(36)}$, and others have described limited hypothyroxinaemia in TR $\alpha 1^{-/-}$mice $^{(37)}$. These data suggested that the TR $\alpha$ proteins might balance the action of TR $\beta$ receptors and positively control the production of $\mathrm{TH}$. This contradiction is easily resolved if we assume that the absence of the weak repressor, $\mathrm{TR} \alpha$, eliminates the competition between the two types of receptors and enables the stronger repressor, TR $\beta$, to fully exert its repression potential. This assumption is supported by data showing that TR $\beta$ proteins are more efficient than TR $\alpha 1$ in binding the negative TH response element of the TSH promoter and repressing its activity $^{(38)}$. This explains the prevalence of the widespread hypothyroxinaemic state rather than frank hypothyroidism in iodine-deficient areas. However, we at this point are not sure how the gene-specific effect of iodine/TH and $n$ - 3 FA works.

The results raise an intriguing possibility of overcoming some of the refractiveness in children who are given iodine supplementation alone to treat hypothyroidism ${ }^{(39)}$. In fact, based on these results, it could be argued that recovery of iodine deficiency in children may be more complete and accelerated if given a supplementation of $n-3$ FA along with iodine. The beneficial effects of $n-3$ FA under iodine deficiency were even more strengthened by the results that we obtained from the behavioural tests. These results showed that perinatal supplementation of $n-3$ FA to iodinedeficient pups clearly resulted in restoration of key molecular and cellular targets and improved cognitive performance in later life.

Taken together, the present study supports the nutritional benefits of $n-3$ FA in the developing brain and shows its efficacy in reducing neuronal damage under other nutritional deficiencies. Here, we also show complementation provided by $n-3$ FA to iodine supplementation under developmental hypothyroidism and argue for its inclusion as a supplement in treating different nutritional deficiencies in human populations.

\section{Supplementary material}

To view supplementary material for this article, please visit http://dx.doi.org/10.1017/S0007114512005569

\section{Acknowledgements}

This work was supported by grants from the Department of Science and Technology, Government of India (SR/SO/HS/ $95 / 2007$ and SR/SO/HS-0054/2010 to M. M. G.) and Senior Research Fellowship (no. 3/1/2/30/09-RHN) from the Indian Council of Medical Research (A. P.). All authors contributed to the preparation of the manuscript. M. M. G., D. R. M. and R. A. S. designed the study. A. P. and V. M. were responsible for the feeding protocol; A. P. and P. K. for the collection of tissue and blood samples; and A. P. and L. R. for neurobehavioural testing. This work constitutes the PhD thesis of A. P., and all biochemical assays were performed by him. A. P. and V. M. also carried out the statistical analysis. The authors declare that they have no conflict of interest in relation to this work.

\section{References}

1. Andersson M, Karumbunathan V \& Zimmermann MB (2012) Global iodine status in 2011 and trends over the past decade. J Nutr 142, 744-750.

2. Lavado-Autric R, Auso E, Garcia-Velasco JV, et al. (2003) Early maternal hypothyroxinemia alters histogenesis and cerebral cortex cytoarchitecture of the progeny. J Clin Invest 111, 1073-1082.

3. Berbel P, Mestre JL, Santamaria A, et al. (2009) Delayed neurobehavioral development in children born to pregnant women with mild hypothyroxinemia during the first month of gestation: the importance of early iodine supplementation. Thyroid 19, 511-519.

4. Babu S, Sinha RA, Mohan V, et al. (2011) Effect of hypothyroxinemia on thyroid hormone responsiveness and action during rat postnatal neocortical development. Exp Neurol 228, 91-98.

5. Singh R, Upadhyay G, Kumar S, et al. (2003) Hypothyroidism alters the expression of $\mathrm{Bcl}-2$ family genes to induce enhanced apoptosis in the developing cerebellum. J Endocrinol 176, 39-46.

6. Bhanja S \& Chainy GB (2010) PTU-induced hypothyroidism modulates antioxidant defence status in the developing cerebellum. Int J Dev Neurosci 28, 251-262.

7. Sinha RA, Pathak A, Kumar A, et al. (2009) Enhanced neuronal loss under perinatal hypothyroidism involves impaired neurotrophic signaling and increased proteolysis of p75(NTR). Mol Cell Neurosci 40, 354-364.

8. Sinha RA, Khare P, Rai A, et al. (2009) Anti-apoptotic role of omega-3-fatty acids in developing brain: perinatal hypothyroid rat cerebellum as apoptotic model. Int J Dev Neurosci $\mathbf{2 7}$, 377-383

9. Bazan NG, Molina MF \& Gordon WC (2011) Docosahexaenoic acid signalolipidomics in nutrition: significance in 
aging, neuroinflammation, macular degeneration, Alzheimer's, and other neurodegenerative diseases. Annu Rev Nutr 31, 321-351.

10. Bogazzi F, Hudson LD \& Nikodem VM (1994) A novel heterodimerization partner for thyroid hormone receptor. Peroxisome proliferator-activated receptor. I Biol Chem 269, 11683-11686.

11. de Lange P, Feola A, Ragni M, et al. (2007) Differential 3,5,3'-triiodothyronine-mediated regulation of uncoupling protein 3 transcription: role of fatty acids. Endocrinology 148, 4064-4072.

12. Liu YY, Heymann RS, Moatamed F, et al. (2007) A mutant thyroid hormone receptor alpha antagonizes peroxisome proliferator-activated receptor alpha signaling in vivo and impairs fatty acid oxidation. Endocrinology 148, 1206-1217.

13. Mano MT, Potter BJ, Belling GB, et al. (1985) Low-iodine diet for the production of severe I deficiency in marmosets (Callithrix jacchus jacchus). Br J Nutr 54, 367-372.

14. Folch J, Lees M \& Sloane Stanley GH (1957) A simple method for the isolation and purification of total lipides from animal tissues. J Biol Chem 226, 497-509.

15. Aebi H (1984) Catalase In Vitro. New York, NY: Academic Press.

16. Das K, Samantha L \& Chainy GBN (2000) A modified spectrophotometric assay of superoxide dismutase using nitrite formation of superoxide radicals. Indian J Biochem Biophys 37, 201-204.

17. Ohkawa H, Ohishi N \& Yagi K (1979) Assay for lipid peroxides in animal tissues by thiobarbituric acid reaction. Anal Biochem 95, 351-358.

18. Beutler E, Duron O \& Kelly BM (1963) Improved method for the determination of blood glutathione. J Lab Clin Med 61, $882-888$

19. Cazala P \& Zielinski A (1983) A Y-maze test reveals the positively reinforcing properties of electrical stimulation of the mesencephalic central gray area. Brain Res 273, 143-146.

20. Morris R (1984) Developments of a water-maze procedure for studying spatial learning in the rat. J Neurosci Methods 11, 47-60.

21. Bradbury J (2011) Docosahexaenoic acid (DHA): an ancient nutrient for the modern human brain. Nutrients 3, 529-554.

22. Moreira JD, Knorr L, Ganzella M, et al. (2010) Omega-3 fatty acids deprivation affects ontogeny of glutamatergic synapses in rats: relevance for behavior alterations. Neurochem Int $\mathbf{5 6}$, 753-759.

23. Schipper P, Kiliaan AJ \& Homberg JR (2011) A mixed polyunsaturated fatty acid diet normalizes hippocampal neurogenesis and reduces anxiety in serotonin transporter knockout rats. Behav Pharmacol 22, 324-334.

24. Karr JE, Alexander JE \& Winningham RG (2011) Omega-3 polyunsaturated fatty acids and cognition throughout the lifespan: a review. Nutr Neurosci 14, 216-225.

25. Innis SM (2007) Dietary ( $n$-3) fatty acids and brain development. J Nutr 137, 855-859.
26. Yavin E, Himovichi E \& Eilam R (2009) Delayed cell migration in the developing rat brain following maternal omega 3 alpha linolenic acid dietary deficiency. Neuroscience 162, 1011-1022.

27. Niculescu MD, Lupu DS \& Craciunescu CN (2011) Maternal alpha-linolenic acid availability during gestation and lactation alters the postnatal hippocampal development in the mouse offspring. Int J Dev Neurosci 29, 795-802.

28. Ryan AS, Astwood JD, Gautier S, et al. (2010) Effects of long-chain polyunsaturated fatty acid supplementation on neurodevelopment in childhood: a review of human studies. Prostaglandins Leukot Essent Fatty Acids 82, 305-314.

29. Schuchardt JP, Huss M, Stauss-Grabo M, et al. (2010) Significance of long-chain polyunsaturated fatty acids (PUFAs) for the development and behaviour of children. Eur J Pediatr 169, 149-164.

30. van Goor SA, Dijck-Brouwer DA, Erwich JJ, et al. (2011) The influence of supplemental docosahexaenoic and arachidonic acids during pregnancy and lactation on neurodevelopment at eighteen months. Prostaglandins Leukot Essent Fatty Acids 84, 139-146

31. Neveu I \& Arenas E (1996) Neurotrophins promote the survival and development of neurons in the cerebellum of hypothyroid rats in vivo. J Cell Biol 133, 631-646.

32. Farooqui AA (2012) n-3 Fatty acid-derived lipid mediators in the brain: new weapons against oxidative stress and inflammation. Curr Med Chem 19, 532-543.

33. Gauthier K, Chassande O, Plateroti M, et al. (1999) Different functions for the thyroid hormone receptors TRalpha and TRbeta in the control of thyroid hormone production and post-natal development. EMBO J 18, 623-631.

34. Morte B, Manzano J, Scanlan T, et al. (2002) Deletion of the thyroid hormone receptor alpha 1 prevents the structural alterations of the cerebellum induced by hypothyroidism. Proc Natl Acad Sci US A 99, 3985-3989.

35. Heuer H \& Mason CA (2003) Thyroid hormone induces cerebellar Purkinje cell dendritic development via the thyroid hormone receptor alpha1. J Neurosci 23, 10604-10612.

36. Fraichard A, Chassande O, Plateroti M, et al. (1997) The T3R alpha gene encoding a thyroid hormone receptor is essential for post-natal development and thyroid hormone production. EMBO J 16, 4412-4420.

37. Wikstrom L, Johansson C, Salto C, et al. (1998) Abnormal heart rate and body temperature in mice lacking thyroid hormone receptor alpha 1. EMBO J 17, 455-461.

38. McCabe CJ, Yarwood NJ, Gurr JA, et al. (1998) Differential regulation of the human thyrotropin alpha-subunit promoter by thyroid hormone receptors alpha1 and beta1. Thyroid $\mathbf{8}$, 601-608.

39. Souza LL, Nunes MO, Paula GS, et al. (2010) Effects of dietary fish oil on thyroid hormone signaling in the liver. J Nutr Biochem 21, 935-940. 